Experiencias en exposiciones contemporáneas de arte

Un estudio en museos de La Plata y Buenos Aires

Lucía Palomeque, Marcela Andruchow

Arte e Investigación (N. ${ }^{\circ} 14$ ), e008, noviembre 2018. ISSN 2469-1488

https://doi.org/10.24215/24691488e008

http://papelcosido.fba.unlp.edu.ar/ojs/index.php/aei

Facultad de Bellas Artes. Universidad Nacional de La Plata

\title{
EXPERIENCIAS EN EXPOSICIONES CONTEMPORÁNEAS DE ARTE Un estudio en museos de La Plata y de Buenos Aires
}

CONTEMPORANY EXPERIENCES

IN ART EXHIBITIONS

A Study in Museums in La Plata and Buenos Aires

\author{
LUCÍA PALOMEQUE \\ palomeque.lu@gmail.com \\ MARCELA ANDRUCHOW \\ marcela andruchow@yahoo.com.ar
}

Facultad de Bellas Artes. Universidad Nacional de La Plata. Argentina

Recibido 7/4/2018 | Aceptado 23/7/2018

\section{Resumen}

Este trabajo presenta los resultados parciales de una investigación sobre exposiciones de arte en museos y en centros de arte ubicados en la ciudad de La Plata y Buenos Aires. A partir de la evaluación de dichas exposiciones y de los modos de recepción de los visitantes, se analizan las estrategias expositivas que despliegan los espacios y su relación con las experiencias que logran generar en los públicos. Las muestras que proponen el diálogo y el intercambio con sus espectadores, y que atienden a sus estilos cognitivos, propician la apropiación de un conocimiento significativo. Cuando los museos encaran los diseños de sus muestras pensando en sus audiencias y con estrategias francamente emocionales consiguen causar experiencias memorables en los visitantes.

\section{Palabras clave}

Exposiciones de arte; experiencias; visitantes; estrategias expositivas

\begin{abstract}
This paper presents the partial results of a research into art exhibitions in museums and art centers in the city of La Plata and Buenos Aires. Taking into account methodologies within the evaluation exhibition and the reception of visitors, strategies exhibition spaces and their relationship with the experiences that generate public are analysed. Exhibitions that proposed dialogue and exchange with their viewers and cater to their cognitive styles encourage the appropriation of a significant knowledge. When museums deal with the designs of their exhibits thinking about their audiences and frankly emotional strategies memorable experiences are caused in visitors.
\end{abstract}

Keywords

Art exhibitions; experiences; visitors; exhibition strategies 
Este artículo presenta los resultados parciales de una investigación enfocada en la observación y el análisis de las estrategias expositivas de museos y de centros de arte contemporáneo ubicados en las ciudades de La Plata y de Buenos Aires. Se parte de la idea de que los museos y los centros de exposiciones, como instituciones públicas, tienen una función social orientada hacia sus audiencias. Con ese fin, las estrategias exhibitivas que despliegan se deben vincular con los modos de recepción de los visitantes, entre otras cuestiones, para lograr en y con sus públicos una experiencia memorable y un aprendizaje significativo -que implica casi siempre el diálogo-. Se trata, entonces, de indagar en cómo las estrategias expositivas pueden variar y ajustarse en función de los modos de recepción de los visitantes, aplicando conceptos y métodos que se vienen desarrollando hace ya varias décadas en museos de otras partes del mundo y tibiamente en nuestro país. Pensar a los visitantes como agentes activos ha dado resultados muy gratificantes para los museos.

Los estudios de público revelan que muchas veces los visitantes describen al espacio museal como «frío, ilegible y demasiado complejo, el diálogo termina; ir al museo no supera la experiencia de caminar en un centro comercial algún fin de semana - hecho que para algunas personas sería más significativo-》 (Rubiales García Jurado, 2014, p. 61). Al respecto, los equipos productores de exposiciones tienen mucha responsabilidad: «Si el público o alguno de los segmentos que lo componen se sienten alienados, indignos o fuera de lugar, es porque queremos que así sea» (Heumann Gurian, 2004, p. 13).

Frente a esto, si consideramos que los públicos son la razón de ser de los museos, los equipos de producción podrían reorientar sus prioridades hacia la experiencia de las audiencias dentro de la muestra y no hacia los objetos que desean exponer. Crear espacios que propicien el diálogo intergeneracional y con los pares, y la construcción de sentidos y la interpretación por parte de los públicos son acciones pertinentes que emergen dentro de las estrategias producidas por los museos. Como sostiene Ricardo Rubiales García Jurado (2014), cuando el encuentro entre los visitantes y la exhibición «se califica como significativo implica, necesariamente, elementos afectivos e intelectuales; motiva la exploración y la proyección de relaciones con eventos, con información o con expresiones vistas anteriormente, es un proceso de búsqueda y de construcción de sentido» (p. 62).

De este modo, cuando el museo ofrece a los visitantes la posibilidad de contraponer su realidad con la realidad expuesta, las audiencias se sienten más involucradas y atraídas. Los objetos presentes en las muestras pueden ser resignificados por todos, muchas veces y de diversas maneras, según las estrategias cognitivas peculiares de cada visitante y su propia red de ideas, de creencias y de afectos. 
Para la autora y consultora independiente de museos Elaine Heumann Gurian (2004), «una exposición es un artefacto cultural que expresa las visiones, los prejuicios y las inquietudes del productor. También permite la contemplación de su contenido» (p. 14). Pero la importancia de los públicos no puede soslayarse ya que son participantes silenciosos que influyen en la creación de la muestra. Por esta razón, cobra sentido explorar las imágenes que los especialistas en museos tienen de sus públicos (Heumann Gurian, 2004). Heumann Gurian sostiene que si dichos profesionales son capaces de examinarse a ellos mismos, podrán lograr una comprensión que les permitirá aproximarse de maneras nuevas y fructíferas a sus muestras y a sus públicos.

A pesar de su relevancia, este tema es arduo de desarrollar porque, según Heumann Gurian (2004), es posible que los gestores de la muestra se sientan incómodos ante estilos de exhibir que faciliten el aprendizaje apelando a los sentidos y a las emociones. Por un lado, estas cualidades no se adecuan a la imagen de intelectuales que desean; por otro, no quieren mostrarse amigables con el público, porque creen que eso le quitara importancia a su trabajo. Las preferencias de los productores de exhibiciones evidencian que solo usan determinados estilos que demuestran sus propios y certeros modos de aprendizaje, evitando aquellos francamente emocionales, que podrían generar experiencias memorables para los públicos (Heumann Gurian, 2004). Enfatizamos, entonces, la importancia de generar experiencias memorables ya que funcionan como canal de conexión entre la exposición y el público, teniendo como resultado una experiencia significativa.

Este trabajo explora las estrategias exhibitivas de los museos a partir de dos metodologías complementarias que se enmarcan en la evaluación del contenido expositivo y en la recepción de los visitantes. Se entiende que estas aproximaciones no agotan los posibles análisis, pero permiten acercarnos a conclusiones que refuerzan las apreciaciones realizadas respecto de los aprendizajes y las experiencias de los visitantes a museos.

\section{Análisis ${ }^{1}$ de las exposiciones}

De los seis casos estudiados en la investigación se presentan dos que resultan significativos. Estos son las exhibiciones temporarias: Paisaje Adyacente -en el Museo de Arte Contemporáneo Latinoamericano (MACLA) - y Cómo atrapar el universo en una telaraña —en el Museo

${ }^{1}$ La metodología de análisis de las exposiciones ha seguido las técnicas de observación y registro a partir de la ficha de crítica de contenido de Alicia Sarno y otros (2005). 
de Arte Moderno de Buenos Aires (MAMBA) - , ambas de grupos de autores, que tuvieron lugar entre marzo y agosto de 2017.

Paisaje Adyacente fue una muestra colectiva de obras de abstracción geométrica pertenecientes a cinco artistas contemporáneos. La misma se llevó a cabo entre junio y julio de 2017 en el MACLA. Si tenemos en cuenta la vista desde el exterior del Pasaje Dardo Rocha, edificio que alberga el MACLA, no se observa ningún banner de comunicación de la muestra. Recién en el hall de entrada se puede ver a la izquierda la sala de exposiciones: su título está colocado sobre una de las jambas de la puerta, mientras que sobre la otra se ubican los nombres de los artistas participantes. El título elegido es de carácter creativo, lo que despierta curiosidad.

Una vez dentro de ese espacio, se observa el texto de sala a un lado de la puerta. Este texto es grande, tipografía legible, extensión medida, a la altura apropiada para la vista, sin embargo, resulta difícil de comprender debido al uso de vocabulario específico. La muestra presenta diecinueve obras de cinco artistas distintos, de las cuales dos son tridimensionales - esculturas - y las restantes diecisiete de formato bidimensional sobre diferentes soportes como madera y lienzo. Se destaca el montaje, ya que por momentos las obras se presentan en grupos, por momentos solas, y también en comunión con la arquitectura de la sala. Si bien el objetivo de la muestra no está explicitado, se lo puede deducir teniendo en cuenta el texto de sala y el título de la exposición. La misión es destacar la idea central de la abstracción geométrica, porque se buscó que el diseño museográfico funcione como un todo, haciendo que las paredes, el piso y las obras se conecten entre sí a partir del juego de líneas y de adyacencias [Figura 1].

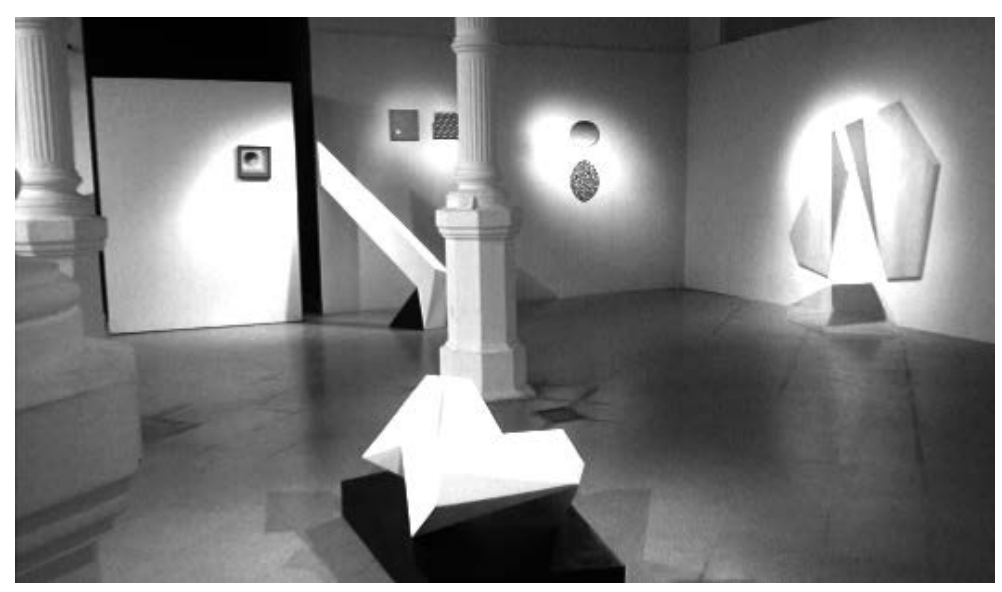

Figura 1. Exposición Paisaje Adyacente (2017). Museo de Arte Contemporáneo Latinoamericano. Foto: Lucía Palomeque 
El objetivo de la exposición es reunir obras del mismo estilo y de artistas contemporáneos latinoamericanos para mostrar el modo pictórico de la abstracción geométrica. Está dirigida a un tipo de público, en particular, a personas que hablen español y que tengan estudios en arte, ya que se necesita de conocimiento previo al no explicarse ni brindarse información sobre las características del movimiento abstracto geométrico. No se desarrolla el recurso de puntos focales y ninguna obra resalta del resto. Todas reciben luz dirigida y el conjunto a modo de paisaje fue el hilo conductor [Figura 2].

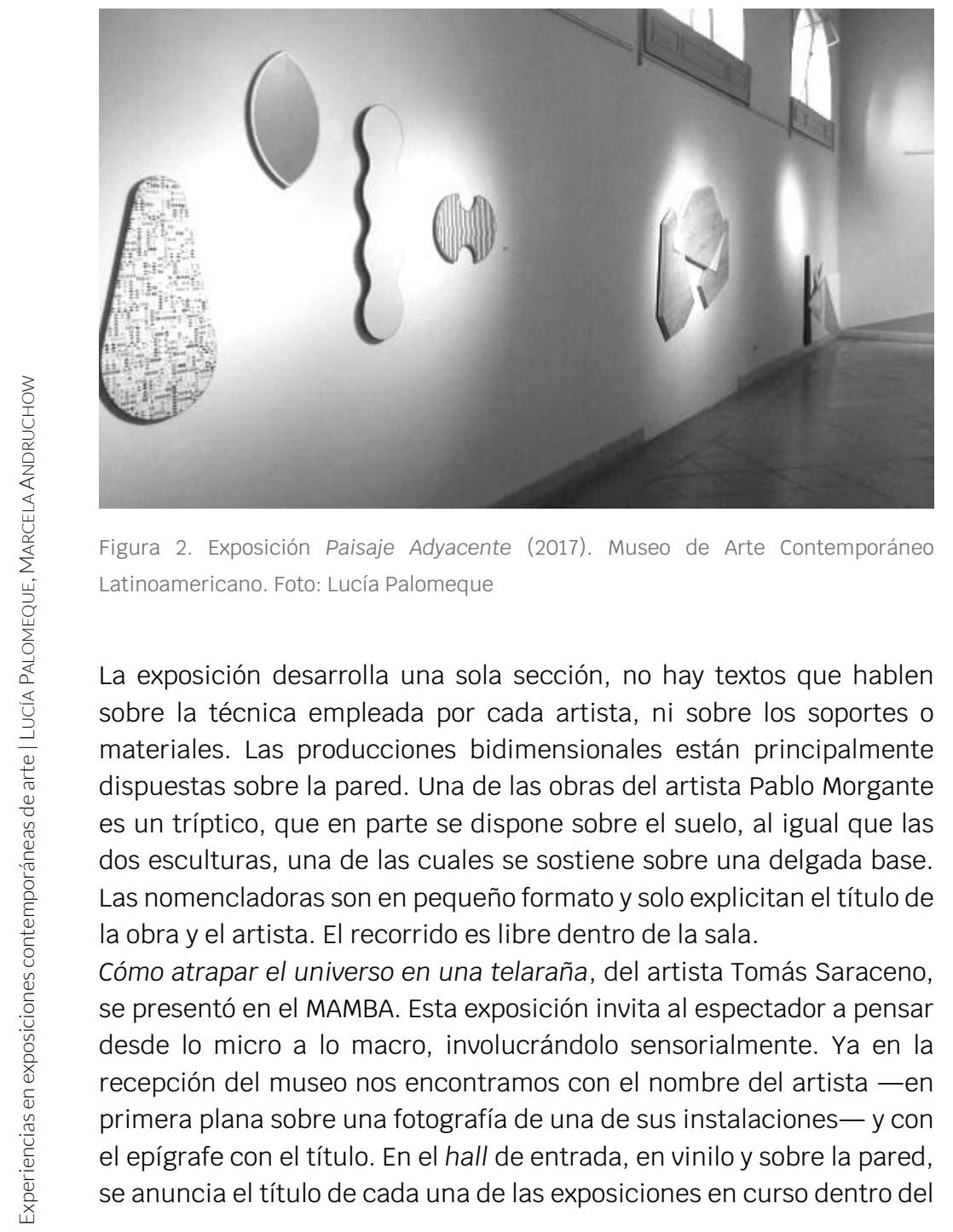


museo, entre las cuales la de Saraceno ocupa dos salas, el subsuelo y el segundo piso, siendo el subsuelo el punto inicial. Dentro del catálogo de la muestra se encuentra un texto de dos páginas, donde se comenta la investigación y el estudio del artista, se explica la idea principal del proyecto y, además, se narra un detrás de escena —el artista, acompañado por científicos, selecciona los arácnidos adecuados para el proyecto- El catálogo también consta de fotografías, texto en español e inglés, y, por último, la biografía del artista. En cuanto al título, Cómo atrapar el universo en una telaraña, se lo puede calificar como creativo, desconcertante y hasta lúdico.

La misión de la muestra pretende compartir la investigación estética y científica del artista argentino Tomás Saraceno, e intentar que el visitante pueda comprender y vivenciar dicho estudio a través de sus sentidos. Como desprendimiento de este objetivo, la exposición se propone incentivar al espectador a pensarse a sí mismo como parte de un todo, como una pieza más dentro del universo, al involucrar sus sentidos. Además, se plantea reflexionar sobre las relaciones entre los diferentes elementos que componen el cosmos, yendo de desde lo microscópico a lo macroscópico.

Si comenzamos el recorrido por las salas del subsuelo, la primera tiene como unidad temática introducir al visitante en la idea central de la investigación del artista, encontrándose el texto curatorial - con traducción al inglés sobre el lado derecho- en gran tamaño sobre la pared. Este presenta al artista y comenta la instalación que el visitante verá en la sala introductoria. Aquí, en la introducción, se proyecta un documental sin sonido pero con subtítulos en español. Tomás Saraceno junto con dos aracnólogos y un camarógrafo buscan, primero en Corrientes y luego en Santiago del Estero, colonias de arañas para comenzar el proyecto en el MAMBA. Simultáneamente, se da información sobre las distintas especies de arañas y sobre la confección de sus telas, y se muestra al público el trabajo en equipo de montaje de la muestra dentro del museo [Figura 3].

Delante de la proyección se colocan sillones y almohadones en el piso, además de una pequeña mesa donde se encuentran más catálogos de la exposición. Detrás de estos sillones hay cuatro vitrinas que contienen documentación, imágenes del universo, fotografías de instalaciones anteriores hechas por el artista y bocetos de telas de araña. Una vez que el visitante es informado, está listo para pasar al siguiente espacio. En ésta se encuentra la instalación The Cosmic Dust Spider Web Orchestra en la que se espera que el espectador se involucre, ya que el texto expuesto allí y el catálogo informan que esta instalación no sería lo mismo sin su presencia. El sonido que produce la araña al tejer se escucha a gran volumen dentro de una sala completamente a 
oscuras, donde solo se puede ver una luz dirigida a la telaraña. Detrás de esta, se proyectan sobre una pared partículas de polvo cósmico, que se mueven como consecuencia del desplazamiento de los visitantes al entrar [Figura 4].

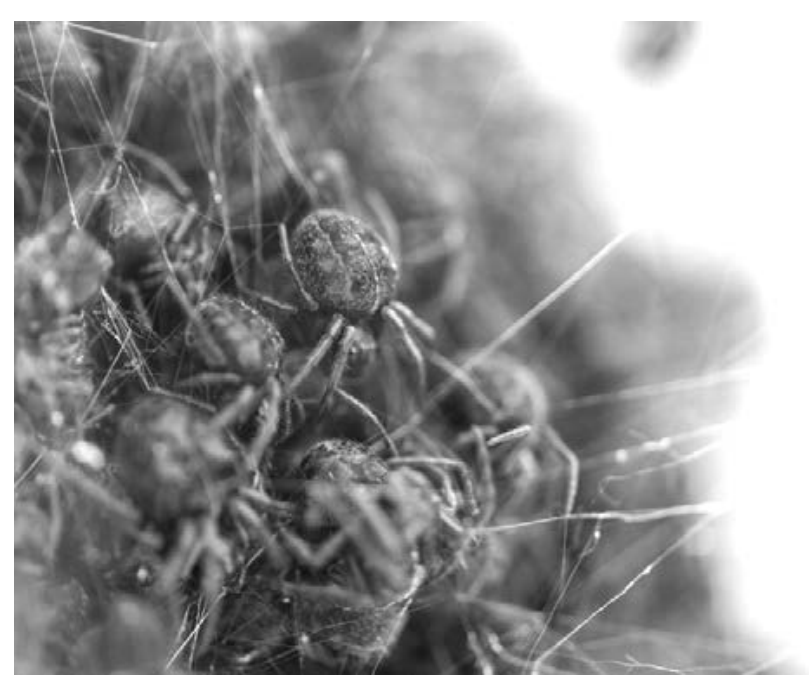

Figura 3. Exposición Cómo atrapar el mundo en una telaraña (2017), Tomás Saraceno. Museo de Arte Moderno de Buenos Aires (MAMBA)

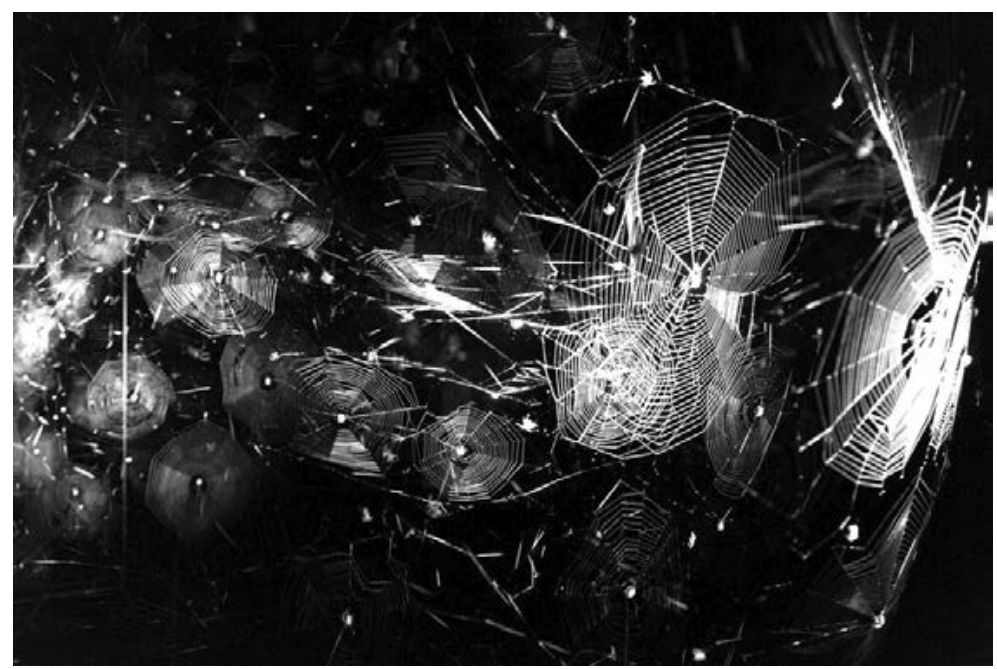

Figura 4. Exposición Cómo atrapar el mundo en una telaraña (2017), Tomás Saraceno. Museo de Arte Moderno de Buenos Aires (MAMBA) 
Se puede decir que esta segunda sección está marcada por lo vivencial, el público vivencia a través de sus sentidos lo que leyó en la sala previa. Luego, al observar la señalética en la pared, se le informa de la existencia de una sala secreta en el segundo piso con el nombre del artista. Una vez allí el personal le comunica a cada visitante las reglas de la sala. La misma solo se puede recorrer perimetralmente, para mantener distancia con la instalación que ocupa el centro.

Esta tercera sección presenta la concreción del proyecto, donde las telas de arañas son las protagonistas y el espectador solo observa la interconexión entre ellas. Una vez dentro de la sala, el visitante se encuentra con lo que ha visto en el documental: el trabajo de ocho colonias de arañas dentro de una sala rectangular con piso negro y paredes negras. Cada telaraña fue tejida siguiendo tensores que van del techo al piso y mediante una luz especialmente dirigida a cada una se observan varios núcleos de distintas formas de telas de araña.

La muestra está compuesta por objetos, instalaciones y un documental presentados como vehículos para comunicar la idea central y como resultado plástico de una investigación científica que genera lazos con el arte. El recorrido en cada sala es libre. Si bien existe una señalética informando al público en qué pisos están las dos salas, no se le indica por cuál comenzar o qué recorrido hacer. Solo hay direccionalidad entre la sala introductoria y la sala dos. Y en la sala del segundo piso, donde el recorrido es perimetral. Se destacan las apoyaturas textuales con el plano de planta y la ubicación del visitante en el edificio.

Estas dos exhibiciones intentan transmitir una idea, pero se diferencian en la dinámica de las pautas expográficas que despliegan. Por un lado, Como atrapar el universo en una telaraña es un proyecto en el que el artista y el museo se involucran en generar una experiencia cognitiva y a la vez muy sensorial. La información es adecuada para comprender el núcleo de la muestra y el montaje es atrapante por la generación de ambientes donde se apela a la recepción del espectador a través de sus distintos sentidos. Se aprecia que en el diseño de la exposición se incluyó a un visitante genérico que se sintiera invitado, intrigado e involucrado emocionalmente. Por otra parte, Paisaje Adyacente responde a una expografía más rígida, en la que los aspectos cognitivos y visuales dominan y el acceso simbólico es reducido. La información es escasa y la dinámica del montaje no motiva afectivamente al público.

Las dos muestras, en función de sus diferencias, producirán entonces distintas experiencias en los visitantes. En ese sentido es importante mencionar a Leslie Bedford (2010), quien hace foco en la imaginación de los visitantes: "La imaginación en realidad es la energía que genera el aprendizaje [...] esta habilidad para pensar sobre lo posible es altamente generadora e involucra la mente activamente en la 
exploración de nuevos terrenos y en la creación de significados» (p. 3). La educación imaginativa está dividida en dos aspectos, el somático y el narrativo. En cuanto al primero, el cuerpo del visitante tiene que estar implicado en la exposición ya que el entendimiento utiliza los sentidos. El mejor camino para lograrlo sería brindarle al espectador elementos que pueda oler o manipular para lograr una conexión a partir del impacto y el asombro. Lo somático tiene que estar acompañado por una narrativa. En relación con este segundo aspecto, Bedford (2010) sostiene que apelar a desarrollar una narrativa en forma de cuento asegura que sus contenidos queden por más tiempo en la mente de los visitantes, porque los cuentos, que suelen remitir a los de la infancia tienen valor emotivo, e implicar a las emociones y a los sentidos en una exhibición colabora en lograr una experiencia memorable. En nuestros casos la muestra que más explora el despliegue de la imaginación como soporte cognitivo es la del MAMBA, que además apela a lo somático y a lo sensitivo.

\section{Mirada de los visitantes}

En cuanto a la recepción por parte de los visitantes, el análisis se basó en los resultados de una breve entrevista acerca de cómo los espectadores perciben, piensan y sienten las exposiciones mencionadas. Para ello, se registraron las respuestas del público de cada muestra a ocho preguntas. La consulta fue efectuada a ocho visitantes, una vez finalizado el recorrido por la exposición. Las preguntas realizadas fueron: 1) ¿qué lo motivó a usted a acudir a esta muestra?; 2) ¿cómo se enteró? A través de qué medios: boca en boca, web, medios masivos de comunicación, folletería, correo electrónico, redes sociales, otro; 3) ¿qué expectativa le generó la muestra para decidirse a visitarla?; 4) ¿tiene alguna relación personal, familiar, amistosa con el artista o expositores?; 5) ¿Conocía previamente la obra de los expositores/artistas?; 6) lo ha movilizado (emotivamente/ intelectualmente) en algún aspecto la exposición?; 7) ¿la muestra satisfizo sus expectativas?; 8) ¿desea aportar algún comentario final?

Con este relevamiento de la recepción se intentó alcanzar una conclusión parcial acerca de las expectativas y de la calidad de experiencia que la visita a cada exposición supuso para los visitantes.

Para los espectadores de Paisaje Adyacente las motivaciones para acudir a la muestra fueron, en igual medida, el interés por el arte como la casualidad de encontrarse dentro del Centro Cultural donde se ubica el MACLA. Los dos principales medios por los que se enteraron de la muestra fueron las redes sociales y la cartelería informativa dentro del 
Centro Cultural. En cuanto a las expectativas, el $60 \%$ de los visitantes tenía la intención de ver arte en general, mientras el 40\% quería ver específicamente las obras expuestas.

Con respecto a este último porcentaje, Paisaje Adyacente expone obras de artistas locales de la ciudad de La Plata, motivo por el cual era posible que alguno de los visitantes conociera o tuviera relación con los artistas expositores. Sin embargo, solo el 20 \% tenía relación con alguno de ellos, en tanto el $80 \%$ no los conocía.

En cuanto a su experiencia en la muestra, ninguno de los encuestados -el 100\% - se sintió movilizado emotiva o intelectualmente. Si bien la expectativa de ver arte se vio satisfecha en el $60 \%$ de los casos, los visitantes manifestaron una apreciación general negativa hacia la muestra -el 40\% de los casos contra el $20 \%$ de mirada positiva-. Es decir que, aunque la exposición satisfizo el interés de ver arte de los encuestados, la mayoría la apreció negativamente.

Por su parte, los visitantes encuestados en Como atrapar el universo en una telaraña responden haberse enterado principalmente de la exposición por la página web del museo y otros por recomendación de conocidos o de familiares. Su motivación para acudir a la muestra fue la de conocer al artista y su obra, aunque otros también la visitaron porque venían a recorrer el museo y se encontraron con las obras de Tomás Saraceno dentro. Una vez en el MAMBA la expectativa de los visitantes ante la muestra fue el el $75 \%$ conocer las obras, ninguno tenía relación con el artista y solo el $25 \%$ de los encuestados conocía su trabajo previamente. La exhibición logró movilizar emocional o intelectualmente al $75 \%$ de los visitantes encuestados, algunos manifestaron miedo, otros expresaron haber sentido involucrados tanto su cuerpo como sus sentidos. La expectativa de los visitantes quedó satisfecha en el $87,5 \%$ de los casos, logrando una mirada positiva ante la muestra del $62,5 \%$.

A partir de las respuestas de los encuestados en cuanto a las expectativas que tienen antes de recorrer las muestras, los intereses presentes en los dos museos fueron conocer las obras en particular y ver arte en general. Para que haya expectativa tiene que haber algo por detrás que la genere, por lo cual se puede apreciar que los museos logran motivar a los visitantes en mayor o en menor medida, transmitiendo el tipo de arte que exhiben en sus muestras, lo que es relevante para la identidad de toda institución.

Otra de las preguntas de la encuesta fue si tenían algún tipo de relación o vínculo con los expositores. Como la mayoría de los artistas se encuentran vivos y algunos de ellos viven en La Plata o en Buenos Aires era posible esperar que las respuestas fueran positivas. Sin embargo, en ambos casos el conocimiento previo de los artistas o de sus obras 
fue muy bajo. Esto podría dirigir más expectativa hacia el diseño expográfico, en función de lograr que la muestra resulte atractiva para el público sin antecedentes sobre los expositores o sus obras.

Finalmente, es importante destacar la amplia diferencia entre el MAMBA y el MACLA respecto de la experiencia (movilizadora o no) que tuvieron los encuestados. En el caso del MAMBA se sintieron motivados, intrigados e incluidos, incluso a través de sus sentidos y su cuerpo. Pero en el caso del MACLA, las respuestas expresaron indiferencia.

Según postula Tam Muro (2016) en su «Breve manifiesto para una exposición inclusiva», para que en una exposición el público se sienta parte, es esperable que se desplieguen estrategias que lo propicie, tales como "dar la oportunidad al visitante de que haga conexiones entre la experiencia que vive en el museo y las de su propia vida», ya que «el desafío consiste en encontrar el punto de conexión entre la experiencia que el museo está tratando de concebir y las experiencias que los visitantes pueden compartir» (s/p). En este sentido, el punto de conexión que encontró el equipo del MAMBA fue el de ambientar una de las dos salas completamente a oscuras con sonido a gran volumen y solo iluminando la obra del artista. Esta experiencia implicó los sentidos de los visitantes encuestados, sus cuerpos estaban involucrados en la exposición, tenían que caminar con cuidado y seguir indicaciones. Además, esta situación logró despertar la inquietud de los visitantes porque algunos manifestaron reflexionar acerca del universo y de las conexiones que surgen dentro de él.

En relación con la apreciación general del público encuestado en las dos exposiciones, lo que se observa es que si bien ambas muestras cubrieron sus intereses porver arte, la mirada general sobre la exposición desarrollada en el MACLA se decanta por una apreciación negativa. Ante esta aparente contradicción los visitantes encuestados expresaron querer que se presente un poco más. Esta frase sin especificidad podría tener muchas motivaciones diferentes, entre ellas, se pueden ofrecer algunas respuestas posibles: las dificultades de acceso simbólico al texto introductorio, la ausencia de material informativo sobre las obras que complemente la cédula con título y autor. En efecto, algunos visitantes expresaron su deseo de encontrarse con las palabras de los artistas y con sus propias ideas acerca de las obras. Ricardo Rubiales García Jurado (2014) describe esta situación comentando que cuando ingresa al museo un visitante que no tiene un amplio conocimiento sobre lo expuesto, se encuentra ante una situación a la que necesita encontrarle un significado, es decir que cuando se ha pensado en las audiencias a las que se dirigen las exposiciones, lo deseable es lograr que se establezca un diálogo entre las ideas planteadas por los curadores y los visitantes. 


\section{Conclusiones}

En relación con la mirada de los visitantes, los puntos a destacar son que acudieron a las muestras para conocer las obras expuestas ya que la mayoría no tenía saberes previos sobre ellas o sus autores. En el caso del MACLA los encuestados expresaron indiferencia respecto de la muestra, mientras que en el del MAMBA, por el contrario, la mayoría se vio involucrada en la propuesta del museo. Sin embargo, las expectativas de ver arte fueron satisfechas en ambas situaciones museos.

A partir de estos limitados resultados se puede pensar en que el MAMBA tuvo en cuenta sensiblemente a sus posibles visitantes al momento de diseñar el proyecto y el montaje de su muestra, pero el MACLA se concentró más en los objetos a exponer y no logró establecer un diálogo entre la muestra y sus públicos. Al respecto, Heumann Gurian (2004) critica a los trabajadores de los museos y arguye:

[...] muchos pensamos [...] que a las exposiciones con fines estéticos concurren persona visualmente letradas, que perciben las señales visuales de los objetos sin necesidad de ayuda adicional. Pero muchas veces no escribimos leyendas explicativas en museos de arte, en los que tampoco solemos recurrir a técnicas auditivas, olfativas o táctiles (p. 17).

Como se puede apreciar en la exposición del MAMBA, las instalaciones, los objetos, los documentos y el diseño lograron provocar reacciones emocionales y disparar recuerdos y sentimientos. La carga emocional que ponemos en cosas impersonales las transforma en objetos de significado.

A su vez, la exposición de Tomas Saraceno innovó al hacer sentir al visitante parte de la muestra, porque como se vio en el análisis, desde el texto de sala, el catálogo y el personal informando a los visitantes sobre las reglas a cumplir antes de ver las instalaciones, se tuvo en cuenta al espectador como parte de la exposición. En otras palabras, se le dice clara y directamente que sin su visita la obra no sería la misma, lo que sumado a la puesta marca la diferencia al integrar al público. Sin embargo, a pesar de que el museo incluye al visitante, no genera estrategias que permitan que los espectadores ofrezcan devoluciones de sus vivencias o reflexiones acerca de la muestra. La experiencia queda entonces, a mitad de camino.

En este sentido puede ser renovador apelar a las formas de la museología crítica. Ésta propone fomentar múltiples lecturas generadas a través de espacios de duda y de pregunta, de esta manera el discurso del museo ya no sería disciplinar o afirmativo, sino que sería un espacio integrador 
y relacional. Para poder llegar a una museología crítica, el visitante apenas ingresa al museo y a las exposiciones tiene que poder entrar en diálogo con la obra. La exposición tiene que dar el primer paso para generar un diálogo multidimensional, de otro modo la visita no alcanza a ser una experiencia memorable.

Para Silvia Alderoqui (2012), «el aprendizaje en el museo puede ser pensado como una conversación elaborada, porque la conversación es el proceso más significativo y ocurrente en la experiencia del museo» (p. 20). La autora se refiere a que entablar un diálogo con los visitantes es la mejor manera de conocerlos y, como acto seguido, la mejor manera para desarrollar las exposiciones. De este modo, se abre camino a una construcción compartida, dándole lugar a los espectadores para que puedan intervenir, participar y dialogar en un espacio que fue pensado para ellos. Al mismo tiempo, la importancia del diálogo radica en que si el visitante logra ponerse en contacto con la exposición, esta experiencia no sólo queda en su memoria - lista para ser transmitida a otros posibles futuros espectadores-, sino que las obras se vuelven valoradas, resignificadas y apropiadas.

Por otro lado, el museo podría generar expectativas en los visitantes antes de que acudan a la muestra, lo que se lograría nuevamente entablando un diálogo. Ricardo Rubiales García Jurado reconoce que se puede producir un diálogo a partir de la puesta en valor del contexto personal del visitante, para lo cual lo ideal es vislumbrar los vínculos intelectuales y emocionales entre el público y la exposición. Con ese objetivo, la propuesta debe plantearse desde los visitantes y no desde la propuesta curatorial. Las exposiciones basadas sólo en las directrices curatoriales terminan el día de la inauguración, pero en verdad, allí deberían empezar, justo cuando los visitantes entran en escena «toda persona trae a su experiencia un bagaje —intelectual y artístico—; aún más, un contexto socio-cultural que define lecturas y acercamientos» (Rubiales García Jurado, 2014, p. 64).

\section{Referencias}

Alderoqui, S. (2012). Los visitantes como patrimonio. El Museo de las Escuelas. Recuperado de http://www.bnm.me.gov.ar/giga1/documentos/ EL005629.pdf

Bedford, L. (17 de marzo de 2010). Trabajar en modo subjuntivo. La imaginación del público como núcleo de la exposición. Ponencia presentada en Museos: nuevos desafíos. Espacio Fundación Telefónica, Buenos Aires, Argentina. 
Heumann Gurian, E. (2004). La sociedad de los artistas. Historias y debates en Rosario. [Catálogo]. Rosario, Argentina: Museo Municipal de Bellas Artes Juan B. Castagnino.

Heumann Gurian, E. (2015). Layering para exposiciones en museos: una introducción. Estrategias para pensar las exposiciones. En Layering en museos. Diseño de exhibiciones a la medida del visitante. Un estudio de caso (pp. 10-14). Recuperado de http://nuevamuseologia.net/wp-content/ uploads/2016/08/layeringmuseo.pdf

Morgante, P., Arditto, L.; Boer, G.; Calvo, V.; Carbia, F.; (2017). Paisaje Adyacente [Exposición]. La Plata, Argentina: Museo de Arte Contemporáneo Latinoamericano. Recuperado de http://www.macla.com.ar/ exposiciones/2017/paisaje-adyacente-arditto-boer-calvo-carbia-y-morgante Muro, T. (2016). Breve manifiesto para una exhibición inclusiva. Recuperado de https://www.facebook.com/tammuro

Rubiales García Jurado, R. (2014). Notas sobre arte, aprendizaje y museos. Nierika, 3(6), 60-69. Recuperado de http://revistas.ibero.mx/arte/uploads/ volumenes/6/pdf/NIERIKA-NUM6.pdf

Saraceno, T. (2017). Cómo atrapar el mundo en una telaraña [Exposición]. Buenos Aires, Argentina: Museo de Arte Moderno de Buenos Aires. Recuperado de http://www.buenosaires.gob.ar/museoartemoderno/ tomas-saraceno-como-atrapar-el-universo-en-una-telarana

Sarno, A.; Lloret, F.; Gutiérrez Marx, G.; Grandi, E. (2005). La crítica de exhibiciones. Una propuesta innovadora que pone en crisis las puestas museográficas. En M. Bonnin y M. J. Fernández (Comps.), Conservación, educación, gestión y exhibición en museos (pp. 279-305). Córdoba, Argentina: Red Jaguar, Brujas. 